\title{
FOGÃO À LENHA PORTÁTIL METÁLICO DE TECNOLOGIA MELHORADA PARA
} MENOR CONSUMO DE LENHA

\author{
Bruna Francini Lupepsa 1; Gilmara de Oliveira Machado ${ }^{2}$ \\ 1. Pós-graduanda em Bioenergia pela Universidade Estadual do Centro Oeste do \\ Paraná. UNICENTRO, Irati-PR em bruflupepsa@hotmail.com \\ 2. Professora Doutora do Departamento de Engenharia Florestal-UNICENTRO. Irati, \\ PR, Brasil.
}

Recebido em: 06/04/2019 - Aprovado em: 10/06/2019 - Publicado em: 30/06/2019
DOI: 10.18677/EnciBio_2019A178

\begin{abstract}
RESUMO
Os fogões à lenha tradicionais apresentam queima incompleta da lenha, gerando poluentes ambientais em sua fumaça tóxica e cheia de fuligens, sendo que a energia gerada não é totalmente aproveitada na cocção de alimentos. Existe a necessidade de melhorar tecnologicamente os fogões tradicionais, aumentando a eficiência energética, para que haja menor consumo de combustível. Esta pesquisa teve como objetivo principal avaliar por meio de modelagem estatística quatro protótipos de fogões à lenha portátil de tecnologia melhorada. Os Fogões à lenha foram construídos com materiais metálicos de baixo custo e isolamento térmico da câmara de combustão, realizado com lã de rocha. Foi utilizado como combustível lenha de Eucalyptus spp proveniente de plantio florestal. Os fogões foram avaliados por meio da eficiência, potência calorífica e consumo de lenha. A equação de regressão expressa uma correlação positiva entre potência e eficiência sendo negativa a correlação entre eficiência e consumo de lenha, demonstrando que quanto mais eficiente é o fogão menor o consumo de lenha e maior a potência calorífica.
\end{abstract}

PALAVRAS-CHAVE: cocção de alimento; eficiência energética; energia renovável.

\section{PORTABLE METALLIC COOKSTROVE OF IMPROVED TECHNOLOGY TO DECREASE FUELWOOD CONSUMPTION}

\begin{abstract}
Traditional cookstoves present incomplete burning of fuelwood, generating environmental pollutants in their toxic smoke and filled with soot, and the energy generated is not fully utilized in the cooking of food. There is a need to improve traditional stoves technologically, to increase their energy efficiency, and to decrease fuel consumption. The main objective of this research is to evaluate four prototype of improved cookstoves by means of statistical modeling. The cookstoves were built with low-cost metal materials and thermal insulation around the combustion chamber, made with rock wool. Eucalyptus spp was used as fuelwood from forest plantations. The cookstoves were evaluated by efficiency, heat power and fuel consumption. The regression equation expresses a positive correlation between heat power and efficiency, and the correlation between efficiency and consumption is negative,
\end{abstract}


demonstrating that the more efficient the stove is, the lower the fuel consumption and the higher the heat power.

KEYWORDS: cooking food; energy efficiency; renewable energy.

\section{INTRODUÇÃO}

O aumento da demanda mundial por energia eleva cada vez mais a pressão sobre o ambiente com empresas petrolíferas investindo em novas tecnologias buscando o petróleo em locais de difícil acesso, camadas de pré-sal ou em regiões inabitáveis como o ártico. O impacto ambiental de uma atividade exploratória, como a da exploração de petróleo, é suficiente para reavaliar sua real necessidade, buscando alternativas que reduzam drasticamente as emissões de $\mathrm{CO}_{2}$ para evitar uma catástrofe climática (GREENPEACE, 2013).

O desafio deste século é evitar as mudanças climáticas causadas pelo aquecimento global, pois, se a temperatura média mundial aumentar $8^{\circ} \mathrm{C}$ até 2100 as alterações dos sistemas climáticos e os prejuízos nos ecossistemas tendem a ser catastrófico. Logo, diversificar a matriz energética seria uma solução viável, diminuindo o consumo de combustíveis fósseis. Tendo como possibilidade a escassez do petróleo a médio e longo prazo e somando as exigências legais impostas para a construção de hidrelétricas de grande porte no Brasil, as fontes de energia alternativa deverão ter maior participação, onde possivelmente haverá uma tendência no aumento no consumo energético (GREENPEACE, 2013).

A presença das energias renováveis na matriz energética representa a geração de energia mais limpa, onde se libera menos poluentes prejudiciais ao meio ambiente e aos seres vivos. São soluções tecnicamente acessíveis em praticamente todas as regiões do mundo. No Brasil a matriz energética possui maior diversificação, com uma participação de 43,5\% de energia renovável, sendo construída por: $17.5 \%$ de biomassa da cana, $12.6 \%$ hidráulica, $8.0 \%$ lenha e carvão, sendo $5.4 \%$ lixívia e outros renováveis; porém, as participações das energias não renováveis têm: $36.5 \%$ petróleo, $12.3 \%$ gás natural, $5.5 \%$ carvão mineral, $1.5 \%$ urânio e $0.7 \%$ outras fontes não renováveis (BEN, 2017).

Uma das biomassas que apresenta grande potencial no cenário brasileiro, tanto no cultivo como no aproveitamento energético, é proveniente do eucalipto, devido ao fato de ser uma planta que se adapta muito bem ao solo brasileiro, possuindo crescimento rápido com ciclo curto de corte de aproximadamente sete anos (BRASIL, 2014). Com origem Australiana, o eucalipto pertence ao Gênero Eucalyptus que abrange mais de seiscentas espécies catalogadas, em terras brasileiras encontrou condições favoráveis para seu crescimento rápido, favorecendo seu índice de produtividade. Os plantios de eucalipto ocupam 5.6 milhões de hectares da área total de florestas plantadas no país que totaliza 7.8 milhões (EMBRAPA, 2006; ABRAF, 2009; IBA, 2016).

Sendo um material orgânico, que possui energia química em seu interior, a biomassa se enquadra no padrão de energia renovável, podendo ser oriunda de florestas (lenha), vegetações aquáticas e terrestres, resíduos de agricultura, lixo, resíduos animais e outros resíduos industriais. A aplicação tem diversas finalidades como cocção de alimentos em fogões à lenha, aquecimento de ambientes em lareiras, e ainda usados na geração de eletricidade em termoelétricas. Para ocorrer à conversão em energia, às transformações ocorrem em diferentes processos, principalmente por meio da combustão. (GREENPEACE, 2013).

No Brasil cerca de 8,5 milhões de residências utilizam fogões à lenha, localizados principalmente nas zonas rurais, regiões que muito provavelmente tem 
dificuldades no acesso a outras fontes energéticas ou não existe infraestrutura para abastecimento, logo buscam utilizar sistemas para cocção de alimento com a combustão da biomassa (CARVALHO, 2010).

A ineficiência de fogões à lenha tradicionais foi analisada por Almeida (2017), e o fogão apresentou uma eficiência de $0,86 \%$, gerando assim, maior consumo de lenha (BHATTACHARYA et al., 2002). A baixa eficiência ocasiona maior consumo de lenha, pois o aproveitamento da energia não é completo e a queima do combustível ocorre mais rápido, não há isolamento da câmara de combustão, havendo pouca circulação de ar; desta forma, a produção e emissão dos voláteis tóxicos e partículas de fuligem aumentam, gerando poluição no interior das residências.

Diante disto, esta pesquisa teve como objetivo principal a verificação por meio de uma pesquisa exploratória de quatro modelos de fogões construídos com tecnologia melhorada, buscou-se aperfeiçoar o fogão para obter maior eficiência e menor consumo de lenha que o fogão tradicional.

\section{Coleta da Lenha}

\section{MATERIAIS E MÉTODOS}

A lenha foi coletada da área experimental do projeto TUME (Teste de Uso Múltiplos de Eucaliptos) localizada na cidade de Irati, Estado do Paraná. Nesta área encontram plantadas nove espécies florestais Eucalyptus saligna Sm., Corymbia citriodora (Hook.) K.D. Hill \& L.A.S. Johnson; Eucalyptus urophylla S.T. Blake; Eucalyptus grandis W. Hill ex Maiden; Eucalyptus grandis W. Hill ex Maiden $\mathrm{x}$ Eucalyptus urophylla S.T. Blake; Eucalyptus propínqua H. Deane \& Maiden; Eucalyptus pellita F. Muell., Eucalyptus camaldulensis Dehnh. e Eucalyptus tereticornis $\mathrm{Sm}$. As quais foram utilizadas no estudo.

Após a coleta de galhos depositados no solo, as amostras foram classificadas, cortadas na medida padrão de $30 \mathrm{~cm}$ (Figura 1), levadas a estufa em temperatura de $50^{\circ} \mathrm{C}$ por sete dias para secagem das mesmas. Após secagem, a lenha foi acondicionada em laboratório para que atingisse umidade de equilíbrio.

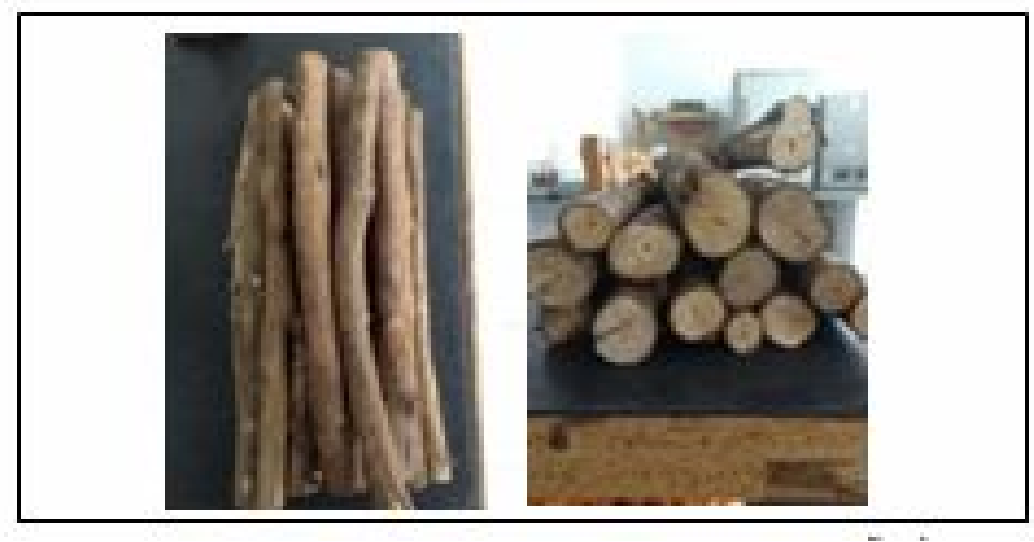

FIGURA 1: Amostras dos toretes utilizados na combustã̃o dos fogões.

Fonte: autores (2019)

\section{Fogão à Lenha de tecnologia Melhorada}

Os fogões à lenha aprimorados foram todos construídos a partir de materiais reutilizáveis acessíveis à comunidade, a câmara de combustão metálica de todos foi construída em formato de "L". Entre a parede interna dos fogões e câmera de combustão se introduziu o isolante térmico constituído por lã de rocha, a qual é 
constituída basicamente de rochas basálticas e fibras minerais e não causam danos ao meio ambiente, esse tipo de tecnologia empregada nestes fogões é conhecido como "Rocket Strove".

Para a pesquisa foram utilizados quatro modelos de fogões, demonstrados na Figura 02, todos foram confeccionados com tecnologia melhorada. O modelo 01 foi construído a partir de um compartimento metálico, com volume de 25 litros, o modelo 02 apresenta volume de 48 litros e a construção partiu de um cilindro de gás usado para empilhadeiras. O modelo 03 apresenta volume de 13,5 litros e foi construído a partir de um cilindro que armazena gás para ar condicionado e o modelo 04 apresenta volume de 60 litros e foi construído a partir de um cilindro metálico. Todos apresentam grelha para suporte da lenha o que facilita a entrada de oxigênio no fogão, melhorando a queima do combustível.

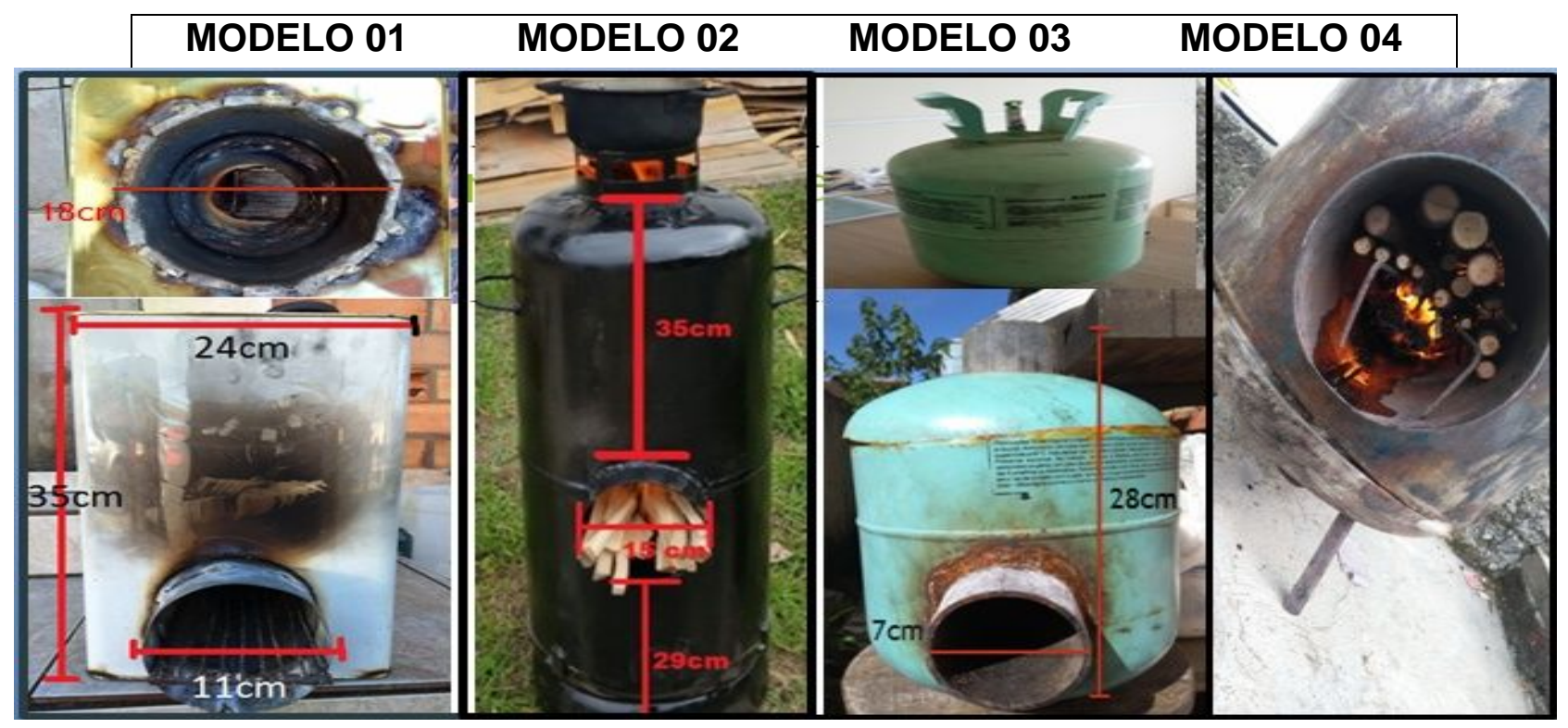

FIGURA 2: Modelos de fogões à lenha usados nesta pesquisa, de 1 a 4 da esquerda para a direita. Fonte: autores (2019)

\section{Medida da eficiência, potência e consumo de lenha do fogão;}

Para cada fogão foram realizados cinco ensaios, que consistiram em pesar uma amostra de combustível (lenha) e uma amostra de água na panela metálica, em seguida colocou-se a panela no fogão, aqueceu, e deixou ferver por 15 minutos. Com isso, foram obtidos dados sobre consumo de lenha utilizada no ensaio, cinzas e quantidade de água evaporada para seguir com as demais análises.

A eficiência de um fogão à lenha é a relação entre o efeito energético útil e o consumo de energia do combustível. A eficiência é calculada pela avaliação da quantidade de calor absorvido pela água em uma panela metálica (Qúti) e a quantidade de calor fornecida pelo combustível (Qlenha) (NOGUEIRA, 2003). A eficiência se obtém através do resultado da razão entre o calor absorvido pela água (energia útil) e a energia liberada pela lenha (Equação 01).

$$
E_{f}(\%)=100\left(\frac{Q_{\text {útil }}}{Q_{\text {lenha }}}\right)
$$

(Equação 01) 
A potência do fogão é a quantidade de energia térmica útil, proveniente da queima da lenha, utilizada para aquecer e ferver a água pelo tempo de 15 minutos. A potência esta diretamente relacionada com o calor produzido pela lenha através do seu poder calorífico, tempo de queima da lenha e eficiência. A potência do fogão é dada pela Expressão 02.

$$
\operatorname{Pot}(k W)=\frac{m_{\mathrm{q}} P C U_{l} E_{f}}{t}
$$

Onde: $m_{q}$ é a massa de lenha queimada no fogão $(\mathrm{kg})$;

(Equação 02)

$\mathrm{PCU}_{\mathrm{I}}$ : Poder calorífico útil da lenha $(\mathrm{kg})$

$E_{f}$ : Eficiência do fogão (\%)

t: tempo transcorrido do experimento (seg)

O consumo de lenha do fogão é determinado pela seguinte expressão:

$$
F\left(k g h^{-1}\right)=\frac{m_{q}}{t}
$$

Sendo:

(Equação 03)

$\mathrm{F}$; Consumo de lenha $\left(\mathrm{kgh}^{-1}\right)$

$\mathrm{m}_{\mathrm{q}}$ : A massa de lenha queimada $(\mathrm{kg})$

$\mathrm{t}$ : Tempo transcorrido no experimento (h).

Para uma melhor avaliação dos resultados, em todos os ensaios, foram calculados os valores médios com seus respectivos desvios-padrão bem como o coeficiente de variação. Para a análise dos dados na modelagem estatística utilizouse o Excel, com regressão da eficiência do fogão em função do consumo de lenha e potência.

\section{RESULTADOS}

As análises de eficiência, potência e consumo de lenha foram realizadas em todos os modelos de fogões, repetidas em cinco vezes, para obtenção dos dados de média, desvio padrão e coeficiente de variação. Observando os dados da Tabela 01 verifica-se que quanto maior a eficiência do fogão, menor é o consumo de lenha e maior a potência.

TABELA 01 - Sumário dos Dados dos diferentes fogões à lenha de tecnologia melhorada.

\begin{tabular}{lccc}
\hline Fogões à lenha & $\mathbf{E}_{\mathbf{f}}(\%)$ & $\mathbf{F}(\mathbf{k g} / \mathbf{h})$ & Pot $(\mathbf{k W})$ \\
\hline Modelo 1 & $23.84 \pm 6.09$ & $0.71 \pm 0.14$ & $0.69 \pm 0.08$ \\
& $(25.5)$ & $(19.7)$ & $(12.2)$ \\
Modelo 2 & $9.50 \pm 3.18$ & $1.48 \pm 0.54$ & $0.53 \pm 0.06$ \\
& $(33.4)$ & $(36.8)$ & $(13.1)$ \\
Modelo 3 & $11.48 \pm 2.04$ & $0.71 \pm 0.37$ & $0.34 \pm 0.19$ \\
& $(17.7)$ & $(51.7)$ & $(56.2)$ \\
Modelo 4 & $10.58 \pm 2.99$ & $0.67 \pm 0.20$ & $0.27 \pm 0.05$ \\
& $(28.2)$ & $(32.1)$ & $(19.3)$ \\
\hline
\end{tabular}

Cada média é seguida pelo respectivo desvio-padrão. O coeficiente de variação encontra-se entre parênteses, sendo Ef eficiência, $F$ consumo de lenha e Pot. potência do fogão. 
A análise de regressão consiste na realização de ajuste estatístico aos dados com o objetivo de verificar a existência de uma relação funcional entre uma variável dependente com uma ou mais variáveis independentes, neste trabalho a análise de regressão foi feita por meio da análise de dados do Excel ajustando a eficiência em função do consumo de lenha e potência dos fogões à lenha. Observa-se que, a equação de regressão é significativa e indica ajuste adequado, pois o valor do pvalor é menor que 0,05 ou $5 \%$ no teste $\mathrm{F}$ da Análise de Variância, ANOVA (Tabela 2).

TABELA 02 - Análise de Variância do ajuste da eficiência em função do consumo de lenha e potência

\begin{tabular}{llllll}
\hline & GL & SQ & QM & Estat. F & p-valor \\
\hline Regressão & 2 & 145.29 & 72.64 & 414.90 & 0.03 \\
Resíduos & 1 & 0.18 & 0,18 & & \\
Total & 3 & 145.0 & & & \\
\hline
\end{tabular}

GL é o grau de liberdade, $S Q$ soma dos quadrados, QM quadrado médio e Estat.F estatística $F$ da ANOVA.

Os coeficientes da equação de regressão também são significativos, o que é evidenciado pelo teste $\mathrm{t}$ com $\mathrm{p}$-valor menor que 0.05 de probabilidade de erro, Tabela 3.

TABELA 3 - Estatística e coeficientes para a equação da eficiência em função do consumo de lenha e potência

\begin{tabular}{llll}
\hline & Coeficientes & Stat. t & p-valor \\
\hline Interseção & 13,5739 & 20,34 & 0,03 \\
$\mathbf{F}(\mathbf{k g} / \mathbf{h})$ & $-34,1750$ & $-20,94$ & 0,03 \\
Pot $(\mathbf{k W})$ & 62,1215 & 28,45 & 0,02 \\
\hline
\end{tabular}

A equação demonstra que há uma correlação positiva entre a eficiência e potência e negativa com o consumo de lenha, pois demonstra que quanto menor 0 consumo de lenha maior será a eficiência do fogão.

$$
E_{f}(\%)=13.5739-34.1750 \times F\left(k g \square^{-1}\right)+62.1215 \text { Pot }(k W)
$$

(Equação 04).

A equação de regressão indica que um fogão mais eficiente consome menor quantidade de lenha, promovendo assim, um maior aproveitamento do calor liberado para a cocção de alimento durante a combustão aumentando também a potência do fogão (Expressão 04).

\section{CONCLUSÕES}

O fogão à lenha aprimorado que apresenta melhor desempenho quanto a eficiência possui menor consumo de lenha e maior potencia térmica Observa-se um melhor aproveitamento da energia gerada pela câmara de combustão com o uso de isolamento térmico, onde o calor é melhor direcionado a panela, logo, novas pesquisas devem ser exploradas com este tipo de melhoria, visando sempre o maior aproveitamento do calor e menor consumo de combustível, o que 
consequentemente diminui a emissão de gases tóxicos causando menos problemas de saúde ao usuário do fogão e também ao meio ambiente.

\section{REFERÊNCIAS}

ABRAF.Associação Brasileira de Produtores de Florestas Plantadas. Ano base 2009. 09/06/2018.

ALMEIDA, M. M. V. D. N.; MACHADO, G. O. ; BANCZEK, E. P (2017). Protótipo de um fogão a lenha como alternativa aos modelos menos eficientes. Universidade Estadual do Centro Oeste, Guarapuava, 2017. 104 p.

Balanço Energético Nacional (BEN) 2017: Relatório Síntese, Ano base 2016.Disponívelem:https://ben.epe.gov.br/downloads/S\%C3\%ADntese\%20do\%20R elat\%C3\%B3rio\%20Final_2017_Web.pdf>. Acesso em 10/06/2018.

BHATTACHARYA, S. C.; ALBINA, D. O.; KHAING, A. M. Effects of selected parameters on performance and emission of biomass-fired cookstoves. Biomass and Bioenergy, v. 23, n. 5,p.387-395,2002. Disponível em:https://www.cabdirect.org/cabdirect/abstract/20023174316>DOI: 10.1016/S0961 9534 (02) 00062-4.

BRASIL, Ministério do Meio Ambiente (MMA). Biomassa. Brasília, 2014. Acesso em 20 ago. 2018

CARVALHO, R. L. T. Eficiência de fogões a biomassa e impactos na qualidade do ar interior. Departamento de Economia, Gestão e Engenharia Industrial.2010. p119. (Mestrado em Sistemas Energéticos Sustentáveis). Universidade de Aveiro.

EMBRAPA. Eucaliptos indicados para plantio no estado do Paraná Documento 129. Colombo, PR. 45p.2006.

GREENPEACE (2013). Revolução Energética, Cenário brasileiro. Disponível em: http://www.greenpeace.org/brasil/Global/brasil/image/2013/Agosto/Revolucao_Energ etica.pdf Acessado em 09/06/2018.

IBA (2016). Indústria Brasileira de Arvores. Relatório Anual 2016. Disponível em: http://iba.org/images/shared/Biblioteca/IBA_RelatorioAnual2016_.pdf. Acesso em 09/01/2019.

NOGUEIRA, L.A.H.; LORA, E.E.S. Dendroenergia: fundamentos e aplicações. ANEEL p.200, Editora Interciencia, 2003. 